\title{
It Pays to Prepare: Human motor preparation depends on the relative value of potential response options
}

Running head: Motor preparation depends on relative value

Eva-Maria Reuter ${ }^{1}$, Welber Marinovic ${ }^{2}$, Jesse Beikoff ${ }^{1,3}$, Timothy J. Carroll ${ }^{1}$

${ }^{1}$ Centre for Sensorimotor Performance, School of Human Movement and Nutrition Sciences, The University of Queensland; ${ }^{2}$ School of Psychology and Speech Pathology, Curtin University, Perth WA 6102, Australia; ${ }^{3}$ School of Psychology, The University of Queensland.

Corresponding author

Eva-Maria Reuter

School of Human Movement and Nutrition Sciences, The University of Queensland, Brisbane, Australia

Phone: +61733656104

E-mail: e.reuter@uq.edu.au 


\begin{abstract}
Alternative motor responses can be prepared in parallel. Here, we used electroencephalography (EEG) to test whether the parallel preparation of alternative response options is modulated by their relative value. Participants performed a choice response task with three potential actions: isometric contraction of the left, the right, or both wrists. An imperative stimulus (IS) appeared after a warning cue, such that the initiation time of a required action was predictable, but the specific action was not. To encourage advanced preparation, the target was presented $200 \mathrm{~ms}$ prior to the IS, and only correct responses initiated within $\pm 100 \mathrm{~ms}$ of the IS were rewarded. At baseline, all targets were equally rewarded and probable. Then, responses with one hand were made more valuable, either by increasing the probability that the left or right target would be required (Exp1; $n=31)$ or by increasing the reward magnitude of one target $(\operatorname{Exp} 2, n=36)$. We measured reaction times, movement vigour, and an EEG correlates of action preparation [lateralised contingent negative variation $(\mathrm{CNV})$ ] prior to target presentation. Participants responded earlier to more frequent and more highly rewarded targets, and movements to highly rewarded targets were more vigorous. The $\mathrm{CNV}$ was more negative over the hemisphere contralateral to the more repeated/rewarded hand, implying an increased neural preparation of more valuable actions. Thus, changing the value of alternative response options can lead to greater preparation of actions associated with more valuable outcomes. This preparation asymmetry likely contributes to behavioural biases that are typically observed towards repeated or rewarded targets.
\end{abstract}

Keywords: EEG/ERP, Action Selection, Motor Planning, Movement Utility, CNV, Lateralised Readiness Potential 


\section{Introduction}

Human and animal behaviour is shaped by the desire to obtain rewards. Expected rewards strongly influence perceptual and motor decisions (Deco G et al., 2013;Mirabella G, 2014;O’Doherty JP, 2011), and the characteristics of goal directed movements (e.g. Hickey $\mathrm{C}$ and van Zoest W, 2012;Sackaloo K et al., 2015; Theeuwes J and Belopolsky AV, 2012). Most work in this area has focused on understanding the influence of reward on the decision process, and involved tasks in which ample time is available to process sensory information, consider alternative options, and plan and execute actions. However, time is limited in many natural scenarios, which might challenge the capacity of motor preparation even when perceptual decisions are trivial. Imagine a fox patiently waiting in front of two mouse holes for its prey to appear. In order to maximise the likelihood of obtaining the reward it seeks, the fox needs to initiate a movement towards one of the holes as quickly as possible upon the appearance of its target. In scenarios like this, there is uncertainty about which action will be rewarding, and once the information becomes available, the time to prepare and perform quick actions is limited. It would therefore seem advantageous to prepare for multiple potential options in advance, so that the required action does not occur too late once sufficient information is available. Indeed, neurophysiological (e.g. Baumann MA et al., 2009;Cisek P and Kalaska JF, 2005;Cisek P and Kalaska JF, 2010;Dekleva BM et al., 2016;Klaes C et al., 2011;Song JH, 2017) and behavioural (Gallivan JP et al., 2015;Gallivan JP et al., 2017; Ghez C et al., 1997;Stewart BM et al., 2013;Stewart BM et al., 2014) results show that we plan, in parallel, multiple potential response options, before implementing one of them. Here we ask whether the preparation of multiple responses is influenced by the expected values of response options. In other words, do we prepare more fully for actions that we expect to be more rewarding?

Shorter reaction times to rewarding stimuli indeed suggest that we prioritise the preparation of more rewarding actions. Work on humans (Chen LL et al., 2014;Manohar SG et al., 2017;Xu-Wilson M et al., 2009) and non-human primates (Bendiksby MS and Platt ML, 2006;Hikosaka O,

2007;Lauwereyns J et al., 2002; Takikawa Y et al., 2002) has shown that saccades are faster to stimuli associated with relatively larger rewards and their trajectories are biased towards previously rewarded locations (e.g. Hickey C and van Zoest W, 2012;Theeuwes J and Belopolsky AV, 2012). Similarly, manual responses are initiated earlier to more rewarding stimuli (Esteves P et al., 2016;Klein P-A et al., 2012; Opris I et al., 2011). However, response time is not a direct measure of motor preparation (Haith AM et al., 2016), as it reflects the accumulated time it takes to identify the response signal, select the appropriate response, prepare and initiate the movement (Rosenbaum 1980). Recently, Haith et al. (2016) proposed a model of motor control in which the time taken to initiate an action is independent from the time it takes to prepare it. Therefore, it is also conceivable that shorter reaction times for stimuli associated with larger rewards do not reflect biased motor preparation, but could be 
due to faster encoding of the response signal, faster response selection, and/or the more rapid initiation of the movement (Klein P-A,Olivier E and Duque J, 2012;Noorbaloochi S et al., 2015).

The long-run value of a response option is defined as the product of its associated reward and the probability of its availability. Thus, the expected value of taking one action over another in a given situation is not only related to expected reward magnitude, but also to the likelihood of which response option will be required (Glimcher PW and Rustichini A, 2004;Milstein DM and Dorris MC, 2007; O’Doherty JP, 2014). In order to maximise rewards/gains over time, individuals should therefore bias preparation towards reponses that are more likely to be required in a given context. In line with this prediction, saccadic and manual reaction times are shorter for more frequently presented stimuli (e.g. Carpenter RH and Williams M, 1995;Klein P-A,Olivier E and Duque J, 2012). Importantly, our recent results demonstrate that such behavioural biases are due partly to a timesensitive process that reflects advanced preparation of actions that are more likely to be required next, in addition to a use-dependent process that is strictly dependent on recent movement history (Marinovic W et al., 2017)

In the current study, we used electroencephalography (EEG) to measure the parallel neural preparation of multiple response options in humans. We manipulated the relative value of left and right hand responses by increasing either reward magnitude or target likelihood for responses made with one hand. Specifically, we recorded lateralised movement-related event-related potential (ERPs) during preparation of three potential actions: isometric force pulses with the left, the right or both wrists. The available preparation time was controlled using a modified version of the timed-response paradigm (Ghez C et al., 1990;Haith AM,Pakpoor J and Krakauer JW, 2016;Marinovic W et al., 2014). Movement-related ERPs, such as the Contingent Negative Variation (CNV; Walter WG et al., 1964) and the lateralised readiness potential (LRP; de Jong R et al., 1988;Gratton G et al., 1988) are reliably observed during response anticipation (for an overview of movement-related cortical potentials see Jahanshahi M and Hallett M, 2003) and are sensitive to the level of motor preparation (Leuthold H and Jentzsch I, 2001;Ulrich R et al., 1998;van den Berg B et al., 2014). Critically, lateralised movement-related ERPs, indexes the preparation of hand-specific response (for reviews see e.g. Eimer M, 1998; Leuthold H et al., 2004). When unilateral responses are cued, the ERP is lateralized as a function of the priming stimulus. Specifically, during motor preparation the ERP recorded over the hemisphere contralateral to the moving limb is larger (more negative) than those recorded from the ipsilateral hemisphere (Gratton G et al., 1990;Leuthold H et al., 1996;Otto D and Leifer L, 1973;Scheibe C et al., 2009;Ulrich R,Leuthold H and Sommer W, 1998;Wild-Wall N et al., 2003). Consequently, contrasting movement-related ERPs between the two hemispheres allows inference about the relative extent of preparation for left or right hand responses. Along with shorter reaction times, we found relatively more negative ERPs over the hemisphere contralateral to the more 
valuable response side just prior to target appearance, demonstrating greater neural preparation of more valuable actions in advance of target encoding.

\section{Methods}

\section{Participants}

Seventy-three healthy students (45 females, 4 non-disclosed) at the University of Queensland, with ages ranging from 17 to $40(M=20.9, S D=4.0$ years $)$, participated in one of two experiments. Recruitment was done through the UQ School of Psychology Research Participation Scheme, and by information flyers, seeking volunteers. Thirty-four participants took part in Experiment 1 and 39 in Experiment 2. All participants were right-handed (Oldfield 1971, as modified by M. Cohen, Staglin IMHRO Center for Cognitive Neuroscience, University of California, Los Angeles, Los Angeles, CA; ttp://www.brainmapping.org/shared/Edinburgh.php), reported to be free of any neurological conditions or recent upper body injuries, and to have normal or corrected-to-normal visual acuity. The study was approved by the ethics committees of the School of Psychology and the School of Human Movement and Nutrition Sciences of the University of Queensland and procedures performed in this study were in accordance with the 1964 Helsinki declaration and its later amendments.

Participants gave written informed consent prior to taking part in the experiment. Participants received cash payments between $\$ 6$ and $\$ 16$ based on their performance in addition to either course credit or a compensation of $\$ 20$ per hour. One participant was excluded from all analyses due to noisy EEG recordings, and five participants were excluded due to low performance levels $(<50 \%$ of valid trials in at least one condition).

Final samples consisted of 31 participants in experiment 1 and 36 in experiment 2. Within each sample participants were randomly assigned to either a left context or right context group (see Table 1 for details on all four subgroups across both experiments).

Table 1: Final sample characteristics. Provided are means and standard deviations

\begin{tabular}{lllll}
\hline & \multicolumn{2}{l}{ Experiment 1: Action Repetition Context } & \multicolumn{2}{l}{ Experiment 2: Action Reward Context } \\
\cline { 2 - 5 } & $\begin{array}{l}\text { Left }(\mathrm{n}=15,9 \\
\text { females, 2 non- } \\
\text { disclosed) }\end{array}$ & $\begin{array}{l}\text { Right }(\mathrm{n}=16,10 \\
\text { females, 2 non- } \\
\text { disclosed) }\end{array}$ & $\begin{array}{l}\text { Left }(\mathrm{n}=18,11 \\
\text { females })\end{array}$ & $\begin{array}{l}\text { Right }(\mathrm{n}=18,15 \\
\text { females })\end{array}$ \\
\hline Age & $23.24(5.86)$ & $20.38(1.89)$ & $19.78(2.80)$ & $20.33(4.51)$ \\
Handedness & $0.84(0.12)$ & $0.78(0.20)$ & $0.75(0.19)$ & $0.73(0.18)$ \\
MVC Left & $80.2(39.0)$ & $70.3(40.0)$ & $72.0(32.0)$ & $68.7(24.7)$ \\
MVC Right & $90.4(31.4)$ & $86.0(48.6)$ & $77.9(29.9)$ & $75.3(27.0)$ \\
\hline
\end{tabular}

Note. Left and Right in the column heading refer to the more frequent response side (Exp. 1), or the response side with the larger reward (Exp. 2). Age is in years; Handedness score ranges from -1 to 1 , with -1 reflecting $100 \%$ left-handedness and 1 reflecting $100 \%$ right-handedness; MVC = maximal voluntary contraction forces in $\mathrm{N}$. 


\section{Experimental Task and Procedure}

Participants were seated $1.2 \mathrm{~m}$ away front of a screen on which the experimental task was displayed. Their wrists and forearms were fitted into a custom made isometric wrist force measuring apparatus, that restricted participants from physically moving their wrists and forearms (6 df force/torque transducer: JR3 Technologies, 45E15AI63-A 400N60S; for details see also de Rugy A and Carroll TJ, 2010;De Rugy A et al., 2012). The forearms were held in a neutral orientation midway between pronation and supination, and all target directed forces were vertical, requiring wrist abduction. The experimental task was programmed with MATLAB (MATLAB R2011a; Mathworks, Natick, MA). It involved participants making isometric wrist force pulses with the left, right, or both hands towards targets appearing on the screen (ASUS, VG278HR, resolution $1920 \times 1080$, running at $120 \mathrm{~Hz})$.

The trials structure is displayed in Figure 1. Before each trial, participants were asked to relax their wrists and look at a fixation cross which was displayed for $100 \mathrm{~ms}$. A red and a green bar were then displayed on the screen. The green bar $(600 \times 10$ pixels) represented the summed force output in the vertical direction, while the red bar $(600 \times 20$ pixels $)$ represented a starting zone, equal to zero force output. If participants relaxed both wrists, the green bar would overlay the red bar, otherwise participants could use the visual feedback to relax any remaining vertical forces. When participants were relaxed, the green bar disappeared, and an auditory warning stimulus occurred, indicating that participants should prepare to make a force pulse in time with an imperative stimulus that would appear1032 ms later. Participants were instructed to synchronize their force pulses with the imperative stimulus. Crucially, the warning stimulus did not inform participants about which hand needed to be used in the current trial, but allowed them to prepare both hands for an impending action. To signal which action was required, a target (50×25 pixels) appeared on the left, right, or middle of the screen, $200 \mathrm{~ms}$ prior to the imperative stimulus, i.e. $832 \mathrm{~ms}$ after the warning stimulus. The location of the target specified which hand(s) should make a force pulse; the left hand for the left target, the right hand for the right target, and both hands for the middle target. Feedback of wrist force pulses was represented on the screen by the vertical movement of a $50 \times 10$ pixel cursor. The starting position of the cursor aligned vertically with the target that was presented in each trial. In order to reach the target participants had to produce $15 \%$ of their maximal voluntary contraction (MVC) for unimanual (lateral) targets, and 15\% of the summed MVC of both hands for the bimanual central target. MVC was measured individually for both hands prior to main experiment (see below for details). The order of trials was pseudorandomised. If forces greater than $3 \%$ of MVC were applied too early (> $100 \mathrm{~ms}$ prior to response stimulus), too late (> $100 \mathrm{~ms}$ after response stimulus), or with the wrong hand, the trial was terminated and the program informed the participant of their specific error. All successful trials (responses with the correct wrist, of at least $95 \%$ of the required force, and initiated within \pm 
$100 \mathrm{~ms}$ of the imperative stimulus time) were rewarded with points. A score screen displayed the points earned in the last trial, as well as the sum of all points earned in the experiment. The score screen was displayed randomly for 500 to $1500 \mathrm{~ms}$ to vary the inter-trial intervals. Participants were informed that points would be earned by correctly reaching the targets with accurate timing and that their total score would correspond to a monetary reward at the experiment's completion, with each point being worth one cent.

\section{[Insert Figure 1 about here]}

In both experiments, participants took part in two experimental blocks of 234 (Exp. 1) or 240 (Exp. 2) trials each. In the baseline block, all targets were equally likely to occur and equally rewarded with two points when successfully reached. In the context block, either the left or the right target appeared more frequently (ratio of left to right targets: 1/3; Exp. 1), or was more rewarding (earning 10 instead of 2 points, Exp. 2). In addition to the greater monetary reward, successfully reaching a rewarded target was followed by a high-pitched 'bing' sound (chosen to sound pleasant). Note that the middle target appeared in $1 / 3$ of all trials in both blocks and experiments. The baseline and the context blocks were both preceded with a practice block of 60 trials under the respective trial conditions, that were not analysed, and participants were explicitly told about the probability and reward manipulations. Participants had a fixed break (60s) in the middle of each of the experimental blocks and could rest as long as needed between blocks. They were further instructed that the experiment could be paused anytime if they required an additional break period. Testing was completed within 2 hour sessions, including time to read and sign the informed consent, the EEG set up, and the experimental testing.

As any pre-target differences in subliminal force magnitude between hands might have influenced the laterality effects in the electrophysiological activity, as well as biased reaction times, we calculated the differences in mean forces output between hands in a $100 \mathrm{~ms}$ time window prior to the target appearance and compared these differences between experimental blocks. Moreover, we determined reaction times from the force output recorded over time based on a sensitive algorithm proposed by Teasdale and colleagues (Teasdale, Bard, Fleury, Young, \& Proteau, 1993). We further calculated the rate of force development, as a measure of response vigour (peak of the first derivative of force over time) and relative peak force (peak force to required force ratio). Statistical analysis was restricted to successful trials only.

\section{Maximum voluntary contraction}

We measured the MVC forces for both wrists of each participant via a custom LabVIEW program (LabVIEW 2011 SP1; National Instruments, Austin, TX) prior to the experimental task. Following a beep, participants were asked to produce as much sustained upwards force as they could for $3 \mathrm{~s}$. Forces were displayed on the screen as a cursor moving within an inverted cone to show the 
direction and relative magnitude of their force. Three trials were conducted for each hand with 10 seconds breaks between trials and the maximal forces obtained for each hand was set as the MVC values for the experiment (see Table 1 for descriptive statistics on MVCs.)

\section{EEG Recording and Processing}

EEG data was recorded with BrainVision Recorder software (Version 1.20.0801; Brain Products, 2014) using a 64-channel active electrode system with $\mathrm{Ag}-\mathrm{AgCl}$ sensors (actiCHamp \& actiCAP, Brain Products, Munich, Germany). Electrodes were placed according to the extended 10-20 system (Jasper HH, 1958). The signal was online referenced to channel Fz, and was recorded with a sampling rate of $2500 \mathrm{~Hz}$ and low-pass filtered at $100 \mathrm{~Hz}$. BrainVision Analyzer 2 (Version 2.1.1.327; Brain Products, 2014) was used for offline analysis of the EEG data. For ERP analyses, the signal was offline down-sampled to $625 \mathrm{~Hz}$ and re-referenced to the mean voltage of all channels. Following this, a $30 \mathrm{~Hz}$ low-pass filter and a $50 \mathrm{~Hz}$ notch filter were applied. The data was then segmented from -200 $\mathrm{ms}$ to $2500 \mathrm{~ms}$ from the warning stimulus. Baseline correction was based on the $-200 \mathrm{~ms}$ to $0 \mathrm{~ms}$ interval and eye movements were corrected using the eye movement correction procedure of Gratton, Coles, and Donchin (1983), based on the channels AF7 and AF8 for the detection of horizontal movements, and FP1 for the detection of vertical movements. EEG activity with a gradient steeper than $5 \mu \mathrm{V} / \mathrm{ms}$, or voltages exceeding $-75 \mu \mathrm{V}$ or $75 \mu \mathrm{V}$, as well as voltage changes of more than 100 $\mu \mathrm{V}$ in a $100 \mathrm{~ms}$ time window, were automatically detected and rejected as artefacts. Artefact rejection was performed on a channel-wise basis, where trial segments identified as containing artefacts were only excluded from further analysis for the channels in which the artefacts occurred.

Figure 2 shows grand average ERPs at channels $\mathrm{Cz}, \mathrm{CPz}, \mathrm{C} 3,4$; CP3,4. Visual inspection of grand average ERPs indicated largest negativity over the vertex at electrode $\mathrm{Cz}$, in line with existing literature on ERPs in task with a fixed interval between warning and response stimuli (Jahanshahi M and Hallett M, 2003). This potentials is commonly referred to as CNV and we extracted the mean $\mathrm{CNV}$ amplitude at $\mathrm{Cz}$ in a 50ms time window prior to target appearance, in order to measure changes in the level of general preparedness over time. More importantly, as we were primarily interested in interhemispheric differences we focused our analysis on the more lateral channels. C3 and C4 electrode sites roughly correspond to the primary motor cortices of the left and right hemisphere respectively (Homan RW et al., 1987;Okamoto M et al., 2004) and represent standard channels within existing literature for the analysis of movement-related ERPs (Jankelowitz S and Colebatch J, 2002; Wright DJ et al., 2011). We therefore inspected ERPs at C3 and 4, as well as the neighbouring FC3 and 4, and CP3 and 4 channels. Visual inspection revealed largest (i.e. most negative) ERPs at the central and centroparietal electrodes (see Figure 2) and we average the signals recorded over these electrodes (left region of interest [ROI], averaged signal from C3 and CP3; right ROI, averaged signal form $\mathrm{C} 4$ and $\mathrm{CP} 4$ ) for further analysis. We refer to these measures as lateralised CNVs. We then calculated a difference waves (Left - Right ROI) and extracted the mean amplitudes in a $50 \mathrm{~ms}$ 
window prior target onset (782-831 ms following the WS) for all successfully completed trials (see Figure 3 for illustration of difference wave calculation in a representative subject).We further flipped the sign of this difference waves for participants who more frequently used the right hand (Exp. 1) or who were more rewarded for the right hand (Exp. 2). In other words for all participants the calculation of the differences was can be summarised as: ROI over hemisphere ipsilateral to the more valuable hand - ROI over hemisphere ipsilateral to the less valuable hand. Consequently, more positive difference wave amplitudes indicate relatively larger preparation of the more valuable response. Note that this analysis is different from the calculation of LRPs, where the calculation of the difference wave is contingent upon the responding hand and the resulting LRP reflects whether the correct or incorrect response has been prepared (for details see Eimer M, 1998).

\section{[Insert Figure 2 about here]}

[Insert Figure 3 about here]

\section{Statistical analyses}

All statistical analyses were carried out using SPSS (IBM SPSS Statistics 22; IBM, Armonk, NY) separately for experiment 1 and 2. We analysed accuracy, median reaction times and mean response vigour using 2 Response type (unimanual, bimanual) 2 Group (left context, right context) $\times$ 2 Block (baseline block, context block) $\times 2$ Hand (less valuable, more valuable) mixed-factor ANOVAs, which was followed up by separate analysis for unimanual (left and right targets) and bimanual (central target) trials. Note that because the factor hand was dependant on the factor group, we did not expect oppositely signed effects between groups. CNV amplitudes at $\mathrm{Cz}$ and ERP difference wave amplitude were analysed using a 2 Group $\times 2$ Block mixed-factor ANOVA.

\section{Results}

\section{Behaviour}

Participants in both experiments managed to perform the task well and successfully responded in time ( $\pm 100 \mathrm{~ms}$ ) with the response stimulus using the correct hand in approximately $90 \%$ of all trials (Exp. 1: accuracy ratio baseline 0.895 \pm SE 0.13, context block: $0.92 \pm$ SE 0.14 ; Exp. 2: accuracy ratio baseline $0.921 \pm \mathrm{SE} 0.10$, block $0.925 \pm \mathrm{SE} 0.10$ ). Accuracy levels for unimanual trials did not change over time in Experiment 1 (accuracy ratio unilateral trials baseline: 0.907 \pm SE 0.01, context block: 0. 918 \pm SE 0.01; main effect of block: $\left.\mathrm{F}(1,29)=1.293, \mathrm{p}=0.265, \mathrm{n}_{\mathrm{p}}{ }^{2}=0.043\right)$ and increased slightly from the baseline to the context block in Experiment 2 (accuracy ratio unilateral trials baseline: $0.926 \pm$ SE 0.01, context block: 0.943 \pm SE 0.01; main effect of block: $F(1,34)=7.142$, $\left.\mathrm{p}=0.011, \mathrm{n}_{\mathrm{p}}{ }^{2}=0.174\right)$. Importantly, however, neither in Experiment 1 nor in Experiment 2 did accuracy changes over time depend on which hand was more rewarded or more probable (Block by hand interaction for $\operatorname{Exp} 1: \mathrm{F}(1,29)=0.168, \mathrm{p}=0.685, \mathrm{n}_{\mathrm{p}}{ }^{2}=.006 ; \operatorname{Exp} 2: \mathrm{F}(1,34)=1.115, \mathrm{p}=0.298$, $\mathrm{n}_{\mathrm{p}}{ }^{2}=.032$ ). Only successful trials were included in all subsequent the analysis. 
Unimanual and bimanual trials were differentially affected by our value manipulations as shown by Response Type $\times$ Block $\times$ Hand interactions $\left(\mathrm{RT}\right.$ : Exp.1, $\mathrm{F}(1,29)=28.167, \mathrm{p}<0.001, \mathrm{n}_{\mathrm{p}}{ }^{2}=$ 0.493; Exp.2, $\mathrm{F}(1,29)=23.850, \mathrm{p}<0.001, \mathrm{n}_{\mathrm{p}}{ }^{2}=0.412$; Vigour: Exp. $\mathrm{F}(1,34)=13.152, \mathrm{p}=0.001$, $\mathrm{n}_{\mathrm{p}}{ }^{2}=0.279$; Peak force: $\left.\operatorname{Exp} 1 \mathrm{~F}(1,29)=6.927, \mathrm{p}=0.013, \mathrm{n}_{\mathrm{p}}{ }^{2}=0.193\right)$. As a consequence, we separately analysed behavioural performance for unimanual and bimanual trials.

Unimanual responses. Descriptive results for reaction times and response vigour are presented in Figure 4 for unimanual responses. In both experiments, reaction times were shorter in the context block than in the baseline block (main effect of block: Exp. 1: $\mathrm{F}(1,29)=15.904, \mathrm{p}<0.001, \mathrm{n}_{\mathrm{p}}{ }^{2}=$ 0.354; Exp. 2: $\left.\mathrm{F}(1,34)=5.622, \mathrm{p}=0.024, \mathrm{n}_{\mathrm{p}}{ }^{2}=0.142\right)$, and were shorter overall for the more valuable response side (main effect of hand: Exp. 1: $\mathrm{F}(1,29)=17.414, \mathrm{p}<0.001, \mathrm{n}_{\mathrm{p}}{ }^{2}=0.375$, Exp. 2: $\mathrm{F}(1,34)=$ $\left.27.235, \mathrm{p}<0.001, \mathrm{n}_{\mathrm{p}}{ }^{2}=0.445\right)$. These main effects were strongly driven by faster initiation of responses to more frequent (Exp. 1) or more rewarding targets (Exp. 2) in the context block. Specifically, block by hand interactions showed that participants responded faster to more frequently presented $\left(\right.$ Exp1: Hand $\times$ Block, $\left.\mathrm{F}(1,29)=85.547, \mathrm{p}<0.001, \mathrm{n}_{\mathrm{p}}{ }^{2}=0.747\right)$ or more rewarding (Exp. 2 : Hand $\times$ Block, $\left.\mathrm{F}(1,34)=49.723, \mathrm{p}<0.001, \mathrm{n}_{\mathrm{p}}{ }^{2}=0.594\right)$ stimuli in the context block. Thus, in both experiments, participants were faster to initiate responses to more valuable targets.

Response vigour was lower in the context block than in the baseline block for non-rewarded targets, but stable across blocks for rewarding targets in Experiment 2 (Hand $\times$ Block, $F(1,34)=$ $\left.8.700, \mathrm{p}=0.006, \mathrm{n}_{\mathrm{p}}{ }^{2}=0.204\right)$. Thus, response vigour was relatively greater for more valuable targets in Experiment 2. There was no statistical evidence of a comparable effect for vigour in Experiment 1 (Hand $\times$ Block, $\left.F(1,29)=1.004, p=0.325, n_{p}^{2}=0.033\right)$; indeed any trend was for vigor to reduce more for movements made to the more frequently presented target (see Figure $4 \mathrm{~b}$ ).

\section{[Insert Figure 4 about here]}

Bimanual responses. For Experiment 1, the analysis of variance revealed no statistically significant changes over time for the bimanual reaction times (main effect of block, $F(1,29)=1.090, p=0.305$, $\mathrm{n}_{\mathrm{p}}{ }^{2}=0.036$ ), or bimanual response vigour (main effect of block, $\mathrm{F}(1,29)=0.461, \mathrm{p}=0.502 \mathrm{n}_{\mathrm{p}}{ }^{2}=$ 0.016). In Experiment 2, bimanual reaction times increased (main effect of block, $F(1,34)=8.343, p=$ $0.007, \mathrm{n}_{\mathrm{p}}{ }^{2}=.197$ ) and vigour reduced over time (main effect of block, $\mathrm{F}(1,34)=11.327, \mathrm{p}=0.002$, $\mathrm{n}_{\mathrm{p}}{ }^{2}=0.250$ ). This suggests that the earlier and more vigorous responses to a rewarded (unimanual) target, comes at a cost not only for responses to the alternative unimanual (non-rewarded) target, but also for bimanual responses to central targets. Interestingly however, in both experiments, reaction times were highly similar between hands for bimanual responses $(<1 \mathrm{~ms}$ differences in median reaction times between hands), suggesting that participants used their hands in synchrony to reach the central target. This observation is further supported by the fact that bimanual responses were overall 
slower than unimanual responses (main effect of response type, Experiment 1: $F(1,29)=41.335, p<$ $0.001, \mathrm{n}_{\mathrm{p}}{ }^{2}=.588$; Experiment 2: $\left.\mathrm{F}(1,34)=56.096, \mathrm{p}<0.001, \mathrm{n}_{\mathrm{p}}{ }^{2}=0.623\right)$, demonstrating a 'bilateral deficit' in force initiation time (Taniguchi Y, 1999;Vieluf S et al., 2013). Again, there were no significant effects for context specific changes in peak forces.

Pre-Target Forces. In order to ensure that any differences between rewarded and non-rewarded hand in the behavioural measures or the lateralised CNVs are not merely a consequence of differences in actual, but sub-threshold for our initiation criterion (i.e. less than 3\% of their MVC), motor output prior to the target appearance (Noorbaloochi S,Sharon D and McClelland JL, 2015), we compared the magnitude of pre-target forces exerted by the left and right hands. We subtracted the mean forces exerted by the valuable hand in a $100 \mathrm{~ms}$ time window immediately prior to target onset from forces exerted simultaneously by the non-valuable hand. In both experiments and in both blocks the force differences between hands did not differ from zero (Force difference between hands Exp 1: Baseline: $=-0.003 \mathrm{~N}, 95 \%$ confidence interval -0.018 to 0.011 ; context block $=0.001 \mathrm{~N}, 95 \%$ confidence interval -0.012 to 0.014; Exp 1: Baseline: $=0.001 \mathrm{~N}, 95 \%$ confidence interval -0.016 to 0.017 ; context block $=0.012 \mathrm{~N}, 95 \%$ confidence interval -0.001 to $0.024 ; \mathrm{t}$ tests against zero, all $\mathrm{p}>.05)$. Moreover, there were no statistically significant changes in the pre-stimulus force differences between hands over time (main effects of block, Experiment 1: $\mathrm{F}(1,29)=0.618, \mathrm{p}=0.438, \mathrm{n}_{\mathrm{p}}{ }^{2}=0.021$; Experiment 2: $\left.\mathrm{F}(1,34)=1.753, \mathrm{p}=0.194, \mathrm{n}_{\mathrm{p}}{ }^{2}=0.049\right)$. Thus, we did not find evidence for any asymmetry in subliminal motor output prior to the target appearance that could bias our results.

\section{Electroencephalography related to movement preparation}

Lateralised CNVs. During the preparation phase lateralised CNVs were more negative over the hemisphere contralateral to the more valuable hand in the context block, suggesting relatively greater preparation of the more valuable response. In other words, difference waves, obtained by subtracting the lateralised CNV activity over the hemisphere contralateral to the more valuable hand from the activity contralateral to the less valuable hand, were more positive in the context block than in the baseline block (see Figure 5). Statistics on the mean amplitudes in the difference waves confirmed that the differences waves were more positive when there was an asymmetry in the value of targets (main effect of block Exp. $1 \mathrm{~F}(1,29)=5.860, \mathrm{p}=0.022, \mathrm{n}_{\mathrm{p}}{ }^{2}=0.168$, Exp. $2 \mathrm{~F}(1,29)=8.180$, $\mathrm{p}=0.007, \mathrm{n}_{\mathrm{p}}{ }^{2}=0.194$, see Figure 6 for mean difference wave values at both time points). Thus participants in both experiments relatively over-prepared the more valuable response in the context block.

\section{[Insert Figure 5 about here]}

\section{[Insert Figure 6 about here]}

Note that we found an unexpected baseline difference between left and right reward groups in Experiment. 2. Specifically, on average, participants who were rewarded more for left hand 
movements had a larger lateralised CNVs over the left hemisphere than the right hemisphere at baseline, whereas participants who were rewarded more for right hand movements had an opposite pattern at baseline. Note that this effect is evident in figures 5 and 6 , where there is a negative baseline value for the difference wave amplitude. This would tend to suggest that participants happened to prepare relatively more for the movements made with the hand that would ultimately be rewarded less strongly - despite the fact that there was no information available to them that would have allowed them to predict the future reward context. This would therefore appear to be a chance outcome, but it raises the possibility that the effects of reward in experiment 2 could have been driven by a normalisation of preparation between the two hands over time, rather than as a genuine consequence of reward. In order to ensure that this is not the case, we considered a sample that excluded 8 participants in Experiment 2 with the most extreme preference for the non-rewarded hand at baseline (4 participants each in the left and right rewarded groups). This removed the baseline differences (see Figure 6, grey dotted lines), but the effect of reward context clearly remained, as shown in Figure 6 $\left(\mathrm{F}(1,26)=5.693, \mathrm{p}=0.025, \mathrm{n}_{\mathrm{p}}{ }^{2}=0.180\right)$. Consequently, we conclude that in both experiments changes in the difference waves reflect over preparation for the more valuable response rather than a regression towards the mean.

Central CNV. In addition to the difference wave between left and right hemispheres, we also investigated changes in the central $\mathrm{CNV}$, recorded at electrode $\mathrm{Cz}$ (see Figure 7), which reflects a general level of motor preparedness independent of laterality (Kononowicz TW and Penney TB, 2016). We found that the central CNV was reduced in the context block with an asymmetric probability of target presentations in Experiment 1 (main effect of block, $\mathrm{F}(1,29)=5.951, \mathrm{p}=0.021$,

$\mathrm{n}_{\mathrm{p}}{ }^{2}=0.170$ ), presumably reflecting a reduction of arousal with time during the experimental testing session, or subjective reduction of task difficultly due to learning (Frömer $\mathrm{R}$ et al., 2016). By contrast, there were no significant changes in central CNV amplitude when asymmetric rewards were introduced in Experiment 2 (main effect of block, $\mathrm{F}(1,34)=1.972, \mathrm{p}=0.169, \mathrm{n}_{\mathrm{p}}{ }^{2}=0.055$ ). We assume that the increase in monetary reward might have counteracted a reduction of general preparedness with time, as previous studies showed an increase of central CNVs when trials are rewarded (e.g. Capa RL et al., 2013;Novak KD and Foti D, 2015;Plichta MM et al., 2013)

\section{[Insert Figure 7 about here]}

\section{Discussion}

Humans and non-human primates are able to prepare in parallel for multiple responses before implementing one of the available options. Here, by use of EEG, we addressed the question of whether such advanced neural preparation is influenced by the relative value of alternative response options in humans. The value of response options was manipulated either by increasing the frequency (Exp. 1) or reward magnitude (Exp. 2) associated with movements of one hand. By requiring 
participants to respond rapidly to presentation of an uncertain target, we encouraged advanced preparation of movements in order to maximise task success (Scheibe C,Schubert R,Sommer W and Heekeren HR, 2009). Importantly, while the time constraints made the task challenging, perceptual encoding and decision making were easy, because target stimuli were non-ambiguous. We found shorter reaction times and greater neural preparation for more valuable response options, as shown by more negative movement-related ERP amplitudes over the hemisphere contralateral to the more valuable response side. Thus, our study provides evidence that motor preparation in humans is influenced by the expected value of potential actions, at a time prior to target stimulus encoding, and action initiation.

Expectations about reward magnitude and the probability of response requirements are both associated with shorter reaction times (Carpenter RH and Williams M, 1995;Esteves P,Oliveira L,Nogueira-Campos A,Saunier G,Pozzo T,Oliveira J,Rodrigues E,Volchan E and Vargas C, 2016;Klein P-A,Olivier E and Duque J, 2012;Opris I,Lebedev M and Nelson RJ, 2011). Our behavioural results complement these previous findings. However, shorter reaction times do not necessarily imply greater preparation of a specific motor response (Haith AM,Pakpoor J and Krakauer JW, 2016), but could also reflect a greater level of general preparation to act (Schevernels $\mathrm{H}$ et al., 2016), an increased level of attention (Anderson BA, 2013;Pool E et al., 2016), a facilitated perceptual encoding of the response signal (Rajsic J et al., 2017), and/or more rapid action selection and initiation (Klein P-A,Olivier E and Duque J, 2012). Therefore, in order to assess motor preparation specifically, here we used EEG to assess lateralised motor preparation prior to the response signal encoding.

Previous studies that addressed lateralised preparation effects mainly employed cueing paradigms, in which a cue specifies which response will be required at a certain probability, or which will be associated with a greater reward. With a cue validty of $\sim 75 \%$ or higher, participants prepare more for the more probable responses, as reflected in differences in lateralised EEG activation between left and right hemipsheres (Gehring WJ et al., 1992;Leuthold H, 2003;Scheibe C,Schubert R,Sommer W and Heekeren HR, 2009). Here, in Experiment 1, we revealed similar effects on lateralised motor preparation when participants had to extract contextual information about target frequency from their action history, in the absence of informative cues. This result can be interpreted in the framework of value-based decision making, since the more probable target gave a higher cumulative payoff over the course of the experiment. In accordance with a potential role for value in motor preparation effects, in Experiment 2, we found lateral bias in motor preparation as a function of reward magnitude.

This finding contrasts with previous work suggesting that lateralised motor preparation has a limited role in response biases due to asymmetric rewards in humans. For example, Noorbaloochi et al. (2015) used a cue to specify whether correct responses with the left or the right hand would have a higher payoff in a difficult perceptual discrimination task. Although the authors found greater 
lateralised EEG activty prior to the appearance of the target favouring the higher paying alternative on a subset of trials, these lateralised effects were a consequence of overt prestimulus motor activation, and predicted the subsequent responses irrespective of sensory evidence. They concluded that bias in motor preparation reflected a fast guess strategy, whereas faster reaction times for rewarding stimuli were due instead to the incorporation of reward in the decision-making process. Similiariy, on the basis of responses to TMS of the primary motor cortex, Klein et al. (2012) concluded that reward has limited effects on motor preparation, and that reaction time benefits are due to more rapid motor initiation for rewarded targets. The evidence for this conclusion was that, although corticospinal excitability was enhanced for responses associated with larger rewards prior to the availability of sensory evidence regarding the upcoming target (i.e. at the instant of response signal presentation), this effect became stronger during the reaction time period, especially for ambiguous response stimuli (Klein P-A,Olivier E and Duque J, 2012). In stark contrast to our study, the perceptual decisions in these the two previous studies were difficult (Klein P-A,Olivier E and Duque J, 2012;Noorbaloochi S,Sharon D and McClelland JL, 2015), while in our study the target stimuli were easlily distinguishable and non-ambigous (e.g. spatially congruent). This non-ambiguity, and the fact that we had high accuracy rates of about $90 \%$ throughout, suggest that in our study participants were less prone to employing guessing strategies. By contrast, we think that after parallel preparation of the alternative responses, participants processed the target prior to releasing the appropriate response. Because the perceptual discrimination was easy, processing the target, rather than guessing should have been effective for our participants. We further speculate that the task requirement to respond within 100 to $300 \mathrm{~ms}$ after the target appeared (i.e. $\pm 100 \mathrm{~ms}$ in time with the response stimulus) made advance parallel preparation of alternative response obligatory. Thus, while in the previous work performance constraints were placed on the decision process, here performance constraints were place on effective, parallel preparation. In these task settings, our findings show that motor preparation of alternative response options is affected by the expected value of response options, at a time prior to target appearance, but in the absence of overt motor output.

Manipulations of contextual information about reward magnitude and target frequency had similar effects on both reaction times and lateralised motor preparation. Reward magnitude and frequency both determine the long-run value of a response option. Thus, in line with earlier notions based on saccadic preparation (Milstein DM and Dorris MC, 2007), our findings suggest that expected value influences motor preparation during parallel planning of alternative manual responses. We further suggest that this prioritised preparation of more valuable actions contributes to behavioural biases that have been reported as a consequence of action history and/or reward history effects (e.g. Chapman CS et al., 2015;Chapman CS et al., 2010;Hickey C and van Zoest W, 2012;Huang V et al., 2011;Spivey MJ et al., 2010; Theeuwes J and Belopolsky AV, 2012;Verstynen T and Sabes PN, 2011; Wong AL and Haith AM, 2017). Such interpretation is in line with our recent behavioural results showing that biases in movement direction, due to action history, reflect advanced preparation 
of actions that are more likely to be required next (Marinovic W,Poh E,de Rugy A and Carroll TJ, 2017). Interestingly, our current work suggests that asymmetric reward magnitude influences both movement vigor and response initiation time, whereas there was no increase in vigour toward targets that were presented more frequently when reward magnitudes were equal. We also found an apparent dissociation between response time and vigor effects in our previous study on action history effects (Marinovic et al 2017). In combination, the data suggest that movement vigor depends on how much reward is expected to be obtained from the action being prepared, and is due to target-related input rather than advanced preparation.

So, how could information about value be integrated into motor preparation process? We measured central CNV and lateralised movement-related ERPs (referred to as lateralised CNVs, see methods for distinction from LRPs). The CNV is related to planning or execution of externally-paced, voluntary movements (Brunia $\mathrm{CH}$ et al., 2012). It reflects both a general cognitive preparedness to process information as well as the specific preparation of motor response (Brunia $\mathrm{CH}$,van Boxtel GJ and Böcker KB, 2012;Leuthold H,Sommer W and Ulrich R, 2004; van Boxtel GJ and Böcker KB, 2004). Accordingly, the CNV signal is thought to have multiple generators, including pre-motor cortices (Praamstra P et al., 2006); supplementary motor area (SMA), inferior posterior parietal cortex, anterior cingulate cortex and insula (Gomez C et al., 2003;Nagai Y et al., 2004). Since nonmotor sources should affect left and right CNV activity similarly, we interpret the changes in the difference wave (gained from the lateralised CNV activity) as modulation of left right activity of premotor activity. This is in line with the notion that late CNV activity, i.e. shortly before the onset of the motor response, is strongly related to motor preparation (Gaillard A, 1977). Moreover, findings in monkeys showing that neurons in the dorsal premotor cortex that encode the spatial properties of response options systematically increased their discharge rate for more valued options during parallel planning of alternative reaches (Pastor-Bernier A and Cisek P, 2011), make it seem highly plausible that these areas are differentially activated also in humans planning manual responses. We further speculate that the value-dependent modulation of lateralised premotor activity in turn could be most likely realised via interactions with the basal ganglia and thalamus (Pastor-Bernier A and Cisek P, 2011), which are so-called secondary regulators or indirect sources of the CNV (Nagai Y,Critchley H,Featherstone E,Fenwick P,Trimble M and Dolan R, 2004). The basal ganglia, and specifically the striatum, have been shown to serve as a "gate" for action selection depending on value, and to disinhibit cortical motor areas responsible for rewarding action via the thalamus (Lintz MJ, 2016). Striatal neurons are well known to code action value (Kim H et al., 2009;Kim S et al., 2012;Lau B and Glimcher PW, 2008;Seo M et al., 2012) and induce disinhibition for movements toward high-value targets (Hikosaka O, 2007;Kawagoe R et al., 1998;Lauwereyns J,Watanabe K,Coe B and Hikosaka O, 2002; Samejima K et al., 2005). In congruence with the lateralised motor preparation effects, the modulation of basal ganglia activity has been previously shown to express reward related response bias (Opris I,Lebedev M and Nelson RJ, 2011; Opris I et al., 2016;Wang AY et al., 2013). Further 
support for the idea that value dependant pre-motor activity is modulated via the basal ganglia stems from findings in Parkinson patients, in whom the integrity of the SMA-striatal-thalamic circuit is disrupted, and who have absent or reduced CNVs (Bötzel K et al., 1995;Ikeda A et al., 1997).

In sum, we showed that expected value, whether manipulated by reward frequency or reward magnitude, modulates the motor preparation of alternative response options. The observed similarity in neural preparation for reward magnitude and frequency effects raises the possibility that they are both mediated by the basal-ganglia-thalamic reward network. By contrast, reward magnitude appeared to have a more potent effect on response vigour than action frequency, suggesting that the two components of value might also differently affect some neural control processes. Importantly, these results were obtained in distinct samples via two different experimental manipulations. Work that combines multiple levels of reward frequency and magnitude manipulation in the same group of people will be needed in the future to provide a more definitive answer to the question of whether the effects of these manipulations truly reflect a composite internal estimate of action value. 


\section{Funding}

This work was supported by a UQ Postdoctoral Research Fellowship (to E.R.) and by the Australian Research Council (FT120100391 to T.J.C. and DP 160102001 to W.M.)

\section{Acknowledgement}

We thank Faten Nadhirah Muhammad Fauzi and Alex Griesinger for passionate help with data collection.

\section{References}

Anderson BA (2013), A value-driven mechanism of attentional selection. Journal of vision 13:7-7. Baumann MA, Fluet M-C, Scherberger H (2009), Context-specific grasp movement representation in the macaque anterior intraparietal area. J Neurosci 29:6436-6448.

Bendiksby MS, Platt ML (2006), Neural correlates of reward and attention in macaque area LIP. Neuropsychologia 44:2411-2420.

Bötzel K, Mayer M, Oertel W, Paulus W (1995), Frontal and parietal premovement slow brain potentials in Parkinson's disease and aging. Movement Disord 10:85-91.

Brunia CH, van Boxtel GJ, Böcker KB (2012) Negative slow waves as indices of anticipation: the Bereitschaftspotential, the contingent negative variation, and the stimulus-preceding negativity. In: The Oxford Handbook of Event-Related Potential Components, vol. (Kappenman S, Luck SJ, eds), pp. 189-207. New York, NY

Capa RL, Bouquet CA, Dreher J-C, Dufour A (2013), Long-lasting effects of performance-contingent unconscious and conscious reward incentives during cued task-switching. Cortex 49:1943-1954. Carpenter RH, Williams M (1995), Neural computation of log likelihood in control of saccadic eye movements. Nature 377:59.

Chapman CS, Gallivan JP, Enns JT (2015), Separating value from selection frequency in rapid reaching biases to visual targets. Vis Cogn 23:249-271.

Chapman CS, Gallivan JP, Wood DK, Milne JL, Culham JC, Goodale MA (2010), Reaching for the unknown: multiple target encoding and real-time decision-making in a rapid reach task. Cognition 116:168-176.

Chen LL, Chen YM, Zhou W, Mustain WD (2014), Monetary reward speeds up voluntary saccades. Front Integr Neurosci 8:48.

Cisek P, Kalaska JF (2005), Neural correlates of reaching decisions in dorsal premotor cortex: specification of multiple direction choices and final selection of action. Neuron 45:801-814.

Cisek P, Kalaska JF, Neural mechanisms for interacting with a world full of action choices, Annu Rev Neurosci, 2010, pp. 269-298.

de Jong R, Wierda M, Mulder G, Mulder $\amalg$ (1988), Use of partial stimulus information in response processing. J Exp Psychol Hum Percept Perform 14:682.

de Rugy A, Carroll TJ (2010), Changes in muscle directional tuning parallel feedforward adaptation to a visuomotor rotation. Exp Brain Res 203:701-709.

De Rugy A, Loeb GE, Carroll TJ (2012), Muscle coordination is habitual rather than optimal. J Neurosci 32:7384-7391.

Deco G, Rolls ET, Albantakis L, Romo R (2013), Brain mechanisms for perceptual and reward-related decision-making. Prog Neurobiol 103:194-213.

Dekleva BM, Ramkumar P, Wanda PA, Kording KP, Miller LE (2016), Uncertainty leads to persistent effects on reach representations in dorsal premotor cortex. eLife 5:e14316.

Eimer M (1998), The lateralized readiness potential as an on-line measure of central response activation processes. Behavior Research Methods, Instruments, \& Computers 30:146-156. 
Esteves P, Oliveira L, Nogueira-Campos A, Saunier G, Pozzo T, Oliveira J, Rodrigues E, Volchan E, et al. (2016), Motor planning of goal-directed action is tuned by the emotional valence of the stimulus: a kinematic study. Sci Rep 6.

Frömer R, Stürmer B, Sommer W (2016), (Don't) Mind the effort: Effects of contextual interference on ERP indicators of motor preparation. Psychophysiology 53:1577-1586.

Gaillard A (1977), The late CNV wave: preparation versus expectancy. Psychophysiology 14:563-568. Gallivan JP, Barton KS, Chapman CS, Wolpert DM, Randall Flanagan J (2015), Action plan cooptimization reveals the parallel encoding of competing reach movements. Nat Commun 6. Gallivan JP, Stewart BM, Baugh LA, Wolpert DM, Flanagan JR (2017), Rapid Automatic Motor Encoding of Competing Reach Options. Cell Rep 18:1619-1626.

Gehring WJ, Gratton G, Coles MG, Donchin E (1992), Probability effects on stimulus evaluation and response processes. J Exp Psychol Hum Percept Perform 18:198.

Ghez C, Favilla M, Ghilardi MF, Gordon J, Bermejo R, Pullman S (1997), Discrete and continuous planning of hand movements and isometric force trajectories. Exp Brain Res 115:217-233.

Ghez C, Hening W, Favilla M (1990) Parallel interacting channels in the initiation and specification of motor response features. In: Attention and performance, vol. 8 (Jeannerod M, ed), pp. 65-293. Erlbaum, Hillsdale.

Glimcher PW, Rustichini A (2004), Neuroeconomics: the consilience of brain and decision. Science 306:447-452.

Gomez C, Marco J, Grau C (2003), Preparatory visuo-motor cortical network of the contingent negative variation estimated by current density. Neurolmage 20:216-224.

Gratton G, Bosco CM, Kramer AF, Coles MG, Wickens CD, Donchin E (1990), Event-related brain potentials as indices of information extraction and response priming. Electroenceph Clin Neurophysiol 75:419-432.

Gratton G, Coles MG, Donchin E (1983), A new method for off-line removal of ocular artifact. Electroenceph Clin Neurophysiol 55:468-484.

Gratton G, Coles MG, Sirevaag EJ, Eriksen CW, Donchin E (1988), Pre-and poststimulus activation of response channels: a psychophysiological analysis. J Exp Psychol Hum Percept Perform 14:331.

Haith AM, Pakpoor J, Krakauer JW (2016), Independence of movement preparation and movement initiation. J Neurosci 36:3007-3015.

Hickey C, van Zoest W (2012), Reward creates oculomotor salience. Curr Biol 22:R219-R220.

Hikosaka O (2007), Basal ganglia mechanisms of reward-oriented eye movement. Ann N Y Acad Sci 1104:229-249.

Homan RW, Herman J, Purdy P (1987), Cerebral location of international 10-20 system electrode placement. Electroenceph Clin Neurophysiol 66:376-382.

Huang V, Haith A, Mazzoni P, Krakauer J (2011), Rethinking Motor Learning and Savings in Adaptation Paradigms: Model-Free Memory for Successful Actions Combines with Internal Models. Neuron 70:787-801.

Ikeda A, Shibasaki H, Kaji R, Terada K, Nagamine T, Honda M, Kimura J (1997), Dissociation between contingent negative variation (CNV) and Bereitschaftspotential (BP) in patients with parkinsonism. Electroenceph Clin Neurophysiol 102:142-151.

Jahanshahi M, Hallett M (2003) The Bereitschaftspotential: Movement-related cortical potentials. Springer Science \& Business Media.

Jankelowitz S, Colebatch J (2002), Movement-related potentials associated with self-paced, cued and imagined arm movements. Exp Brain Res 147:98-107.

Jasper HH (1958), The ten twenty electrode system of the International Federation. Electroenceph Clin Neurophysiol 10:371-375.

Kawagoe R, Takikawa Y, Hikosaka O (1998), Expectation of reward modulates cognitive signals in the basal ganglia. Nat Neurosci 1.

Kim H, Sul JH, Huh N, Lee D, Jung MW (2009), Role of striatum in updating values of chosen actions. J Neurosci 29:14701-14712. 
Kim S, Cai X, Hwang J, Lee D (2012), Prefrontal and striatal activity related to values of objects and locations. Front Neurosci 6.

Klaes C, Westendorff S, Chakrabarti S, Gail A (2011), Choosing goals, not rules: deciding among rulebased action plans. Neuron 70:536-548.

Klein P-A, Olivier E, Duque J (2012), Influence of reward on corticospinal excitability during movement preparation. J Neurosci 32:18124-18136.

Kononowicz TW, Penney TB (2016), The contingent negative variation (CNV): timing isn't everything. Curr Opin Behav Sci 8:231-237.

Lau B, Glimcher PW (2008), Value representations in the primate striatum during matching behavior. Neuron 58:451-463.

Lauwereyns J, Watanabe K, Coe B, Hikosaka O (2002), A neural correlate of response bias in monkey caudate nucleus. Nature 418:413-417.

Leuthold $\mathrm{H}$ (2003), Programming of expected and unexpected movements: effects on the onset of the lateralized readiness potential. Acta Psychol 114:83-100.

Leuthold H, Jentzsch I (2001), Neural correlates of advance movement preparation: a dipole source analysis approach. Cogn Brain Res 12:207-224.

Leuthold H, Sommer W, Ulrich R (1996), Partial advance information and response preparation:

inferences from the lateralized readiness potential. J Exp Psychol 125:307-323.

Leuthold H, Sommer W, Ulrich R (2004), Preparing for Action: Inferences from CNV and LRP. J

Psychophysiol 18:77-88.

Lintz MJ, Context dependence of action selection in the basal ganglia and midbrain, University of

Colorado Denver, Anschutz Medical Campus, 2016.

Manohar SG, Finzi RD, Drew D, Husain M (2017), Distinct Motivational Effects of Contingent and Noncontingent Rewards. Psychol Sci 28:0956797617693326.

Marinovic W, Cheung FL, Riek S, Tresilian JR (2014), The effect of attention on the release of anticipatory timing actions. Behav Neurosci 128:548.

Marinovic W, Poh E, de Rugy A, Carroll TJ (2017), Action history influences subsequent movement via two distinct processes. eLife 6.

Milstein DM, Dorris MC (2007), The influence of expected value on saccadic preparation. J Neurosci 27:4810-4818.

Mirabella G (2014), Should I stay or should I go? Conceptual underpinnings of goal-directed actions. Front Syst Neurosci 8.

Nagai Y, Critchley H, Featherstone E, Fenwick P, Trimble M, Dolan R (2004), Brain activity relating to the contingent negative variation: an fMRI investigation. Neurolmage 21:1232-1241.

Noorbaloochi S, Sharon D, McClelland JL (2015), Payoff information biases a fast guess process in Perceptual decision making under deadline Pressure: Evidence from behavior, evoked potentials, and quantitative model comparison. J Neurosci 35:10989-11011.

Novak KD, Foti D (2015), Teasing apart the anticipatory and consummatory processing of monetary incentives: An event-related potential study of reward dynamics. Psychophysiology 52:1470-1482. O'Doherty JP (2011), Contributions of the ventromedial prefrontal cortex to goal-directed action selection. Ann N Y Acad Sci 1239:118-129.

O'Doherty JP (2014), The problem with value. Neurosci Biobehav Rev 43:259-268.

Okamoto M, Dan H, Sakamoto K, Takeo K, Shimizu K, Kohno S, Oda I, Isobe S, et al. (2004), Threedimensional probabilistic anatomical cranio-cerebral correlation via the international 10-20 system oriented for transcranial functional brain mapping. Neurolmage 21:99-111.

Opris I, Lebedev M, Nelson RJ (2011), Motor planning under unpredictable reward: modulations of movement vigor and primate striatum activity. Front Neurosci 5.

Opris I, Lebedev MA, Nelson RJ (2016), Neostriatal Neuronal Activity Correlates Better with Movement Kinematics under Certain Rewards. Front Neurosci 10:336.

Otto D, Leifer $L$ (1973), Effects of varying magnitude, duration and speed of motor response on contingent negative variation. Electroenceph Clin Neurophysiol 34:695-695. 
Pastor-Bernier A, Cisek P (2011), Neural correlates of biased competition in premotor cortex. J Neurosci 31:7083-7088.

Plichta MM, Wolf I, Hohmann S, Baumeister S, Boecker R, Schwarz AJ, Zangl M, Mier D, et al. (2013), Simultaneous EEG and fMRI reveals a causally connected subcortical-cortical network during reward anticipation. J Neurosci 33:14526-14533.

Pool E, Brosch T, Delplanque S, Sander D (2016), Attentional bias for positive emotional stimuli: A meta-analytic investigation. Psychological Bulletin 142:79-106

Praamstra P, Kourtis D, Kwok HF, Oostenveld R (2006), Neurophysiology of implicit timing in serial choice reaction-time performance. J Neurosci 26:5448-5455.

Rajsic J, Perera H, Pratt J (2017), Learned value and object perception: Accelerated perception or biased decisions? Attention, Perception, \& Psychophysics 79:603-613.

Sackaloo K, Strouse E, Rice MS (2015), Degree of preference and its influence on motor control when reaching for most preferred, neutrally preferred, and least preferred candy. OTJR: occupation, participation and health 35:81-88.

Samejima K, Ueda Y, Doya K, Kimura M (2005), Representation of action-specific reward values in the striatum. Science 310:1337-1340.

Scheibe C, Schubert R, Sommer W, Heekeren HR (2009), Electrophysiological evidence for the effect of prior probability on response preparation. Psychophysiology 46:758-770.

Schevernels H, Bombeke K, Krebs RM, Boehler CN (2016), Preparing for (valenced) action: The role of differential effort in the orthogonalized go/no-go task. Psychophysiology 53:186-197.

Seo M, Lee E, Averbeck BB (2012), Action selection and action value in frontal-striatal circuits. Neuron 74:947-960.

Song J-H (2017), Abandoning and modifying one action plan for alternatives. Phil Trans R Soc B 372:20160195.

Spivey MJ, Dale R, Knoblich G, Grosjean M (2010), Do curved reaching movements emerge from competing perceptions? A reply to van der Wel et al.(2009).

Stewart BM, Baugh LA, Gallivan JP, Flanagan JR (2013), Simultaneous encoding of the direction and orientation of potential targets during reach planning: evidence of multiple competing reach plans. $J$ Neurophysiol 110:807-816.

Stewart BM, Gallivan JP, Baugh LA, Flanagan JR (2014), Motor, not visual, encoding of potential reach targets. Curr Biol 24:R953-R954.

Takikawa Y, Kawagoe R, Itoh H, Nakahara H, Hikosaka O (2002), Modulation of saccadic eye movements by predicted reward outcome. Exp Brain Res 142:284-291.

Taniguchi Y (1999), Effect of practice in bilateral and unilateral reaction-time tasks. Percept Motor Skills 88:99-109.

Theeuwes J, Belopolsky AV (2012), Reward grabs the eye: oculomotor capture by rewarding stimuli. Vision Res 74:80-85.

Ulrich R, Leuthold H, Sommer W (1998), Motor programming of response force and movement direction. Psychophysiology 35:721-728.

van Boxtel GJ, Böcker KB (2004), Cortical measures of anticipation. J Psychophysiol 18:61-76.

van den Berg B, Krebs RM, Lorist MM, Woldorff MG (2014), Utilization of reward-prospect enhances preparatory attention and reduces stimulus conflict. Cognitive, Affective, \& Behavioral Neuroscience 14:561-577.

Verstynen T, Sabes PN (2011), How each movement changes the next: An experimental and theoretical study of fast adaptive priors in reaching. J Neurosci 31:10050-10059.

Vieluf S, Godde B, Reuter E, Voelcker-Rehage C (2013), Effects of age and fine motor expertise on the bilateral deficit in force initiation. Exp Brain Res 231:107-116.

Walter WG, Cooper R, Aldridge V, McCallum W, Winter A (1964), Contingent negative variation: an electric sign of sensori-motor association and expectancy in the human brain. Nature 203:380-384. Wang AY, Miura K, Uchida N (2013), The dorsomedial striatum encodes net expected return, critical for energizing performance vigor. Nat Neurosci 16:639-647. 
Wild-Wall N, Sangals J, Sommer W, Leuthold H (2003), Are fingers special? Evidence about movement preparation from event-related brain potentials. Psychophysiology 40:7-16.

Wong AL, Haith AM (2017), Motor planning flexibly optimizes performance under uncertainty about task goals. Nat Commun 8:14624.

Wright DJ, Holmes PS, Smith D (2011), Using the movement-related cortical potential to study motor skill learning. Journal of motor behavior 43:193-201.

Xu-Wilson M, Zee DS, Shadmehr R (2009), The intrinsic value of visual information affects saccade velocities. Exp Brain Res 196:475-481. 